\title{
Author Correction: Single-cell analysis of developing and azoospermia human testicles reveals central role of Sertoli cells
}

LiangYu Zhao, ChenCheng Yao, XiaoYu Xing, Tao Jing, Peng Li, ZiJue Zhu, Chao Yang, Jing Zhai, RuHui Tian, HuiXing Chen, JiaQiang Luo, NaChuan Liu, ZhiWen Deng, XiaoHan Lin, Na Li, Jing Fang, Jie Sun, ChenChen Wang, Zhi Zhou \& Zheng Li(i)

Correction to: Nature Communications https:/doi.org/10.1038/s41467-020-19414-4, published online 10 November 2020.

The original version of this Article contained an error in figure legend $2 \mathrm{f}$, which incorrectly read '(f) Immunofluorescence co-staining of GATA4 (green) with JUN (red, upper panel), ENO1 (red, middle panel), and DEFB119 (red, lower panel) in human testicular paraffin sections at three ages..' The correct version states '(f) Immunofluorescence co-staining of GATA4 (red) with JUN (green, upper panel), ENO1 (green, middle panel), and DEFB119 (green, lower panel) in human testicular paraffin sections at three ages.'. This has been corrected in both the PDF and HTML versions of the Article.

Published online: 18 June 2021

Open Access This article is licensed under a Creative Commons Attribution 4.0 International License, which permits use, sharing, adaptation, distribution and reproduction in any medium or format, as long as you give appropriate credit to the original author(s) and the source, provide a link to the Creative Commons license,
and indicate if changes were made. The images or other third party material in this article are included in the article's Creative Commons license, unless indicated otherwise in a credit line to the material. If material is not included in the article's Creative Commons license and your intended use is not permitted by statutory regulation or exceeds the permitted use, you will need to obtain permission directly from the copyright holder. To view a copy of this license, visit http://creativecommons.org/licenses/by/4.0/.

(C) The Author(s) 2021 